РОМАНОВ Сергей Юрьевич - к. филос.н., старший научный сотрудник Государственного автономного учреждения Центр гуманитарных исследований Министерства культуры Республики Башкортостан (ГАУ ЦГИ Минкультуры РБ) (450076, г. Уфа, Гафури 13/1; romser76@yandex.ru) ЮСУПОВ Ильшат Фаритович - к. сои. наук., научный сотрудник Института стратегических исследований Республики Башкортостан (450000,г. Уфа, Кирова 15 ilshat_iosopov@таil.ru)

САЛИМГАРЕЕВ Денис Игоревич, аспирант 3-го курса факультета философии и социологии Башкирского государственного университета (450076, г. Уфа, ул. Карла Маркса, 3/4; rетиз-102@ mail.ru)

\title{
СОЦИОЛОГИЧЕСКИЕ АСПЕКТЫ ПРОТЕСТНОЙ АКТИВНОСТИ В РЕСПУБЛИКЕ БАШКОРТОСТАН HA СОВРЕМЕННОМ ЭТАПЕ
}

\begin{abstract}
Аннотация. В статье на основе анализа динамики ситуации вокруг шиханов раскрываются причины и факторы роста протестной активности населения в Республике Башкортостан. По мнению авторов, в регионе сформировалась неповторимая социокультурная среда для протестной активности, своеобразие которой заключается в том, что любой социально значимый вопрос или бытовой конфликт мгновенно получает национальную или конфессиональную окраску, обрастает мифами и слухами, подвергается сакрализации.
\end{abstract}

Ключевые слова: протестная активность, шиханы, социокультурная среда, факторы протестов

$\mathrm{B}$ многочисленных исследованиях по социологии и психологии достаточно исследован феномен «коллективных представлений», возникающих на различных уровнях человеческого сознания и являющихся мотивами для протестной активности. События, которые переживает Республика Башкортостан в 2010-2020 годах, вполне укладываются в описанные М. Вебером, К. Левиным, М. Фуко, Р. Мертоном, К. Юнгом модели с отклонением в ту или иную сторону, связанными с региональными социокультурными и политическими особенностями.

Региональное своеобразие в Республике Башкортостан тесно связано с исторически сложившейся национальной неоднородностью населения, степенью компактности, смешанным и чересполосным проживанием этносов. В результате этого регион представляет собой сложную мозаику, в одной части которой могут формироваться коллективные представления, являющиеся мотивами протестной активности, которые затем распространяются или не распространяются на всю совокупность элементов, приобретая этническую окраску.

Второй важной особенностью региона является то, что он являлся некогда одним из крупных промышленных центров, но в результате распада СССР, краха конструктивистской плановой экономики и приватизации оказался в кризисе. Альтернативы советскому промышленному потенциалу БАССР в регионе за тридцать прошедших лет не создано. Это привело к утрате в общественном сознании стремления к новому, нишу которого стремительно заняла религия, светские и религиозные мифы, распространяемые интерсубъективно и посредством информационных технологий.

Третьей особенностью региона является то, что в течение длительного времени преобладающими в Республике Башкортостан являлись недемократические типы политического режима, основанные на сильной централизованной власти руководителей региона. В результате этого социокультурная мотивация и коллективные представления находили выход в послушании или в крайнем 
редком случае в акциях протеста. Эти две крайних диспозиции стали определяющими для Республики Башкортостан. В период недемократического политического режима пассивность являлась условием выживания. В результате этого в общественном сознании легко укоренялись рациональные и мифологические объяснения, узаконивавшие послушание, пассивность по отношению к конструктивистскому модерну. Иначе говоря, линия на послушание диктовала быть атеистом, сторонником промышленного развития региона и модернизации.

Переплетение трех этих особенностей создало в Республике Башкортостан неповторимую социокультурную среду для протестной активности. Её своеобразие заключается в том, что любой социально значимый вопрос или бытовой конфликт мгновенно получает национальную или конфессиональную окраску, обрастает мифами и слухами, подвергается сакрализации.

Типичным примером проявления региональных особенностей социокультурной мотивации к акциям протеста стала ситуация вокруг шиханов, которая впервые была поднята в 2010 году. Тогда лидером протестной активности против промышленной разработки данных гор стало БОД «Кук Буре». Изначально теме была придана национальная окраска, о чем свидетельствует название программного заявления данной организации «Угроза потери башкирских шиханов». На тот момент ещё не шла речь о сакрализации гор. Авторы выдвигали лишь вотум недоверия членам рабочей группы, созданной для разработки предложений по данному вопросу, и высказывались об опасности «утраты «Стерлитамакскими шиханами» огромного культурологического и этнографического значения, исчезновении зоны отдыха и рекреации для огромного агломерата» 1 . Затем начался этап сакрализации, когда в общественное мнение начали вбрасываться современные мифы, созданные неизвестными авторами. Их было достаточно много, но наиболее типичный пример приводится «Кук Буре» от имени неизвестной бабушки: «вот легенда эта - о четырёх шиханах, что стоят здесь уже многие тысячелетия. Знаете, наверное, как они ещё называются: Торатау - «крепость-гора», Куштау - «парная гора», Юрактау «сердце-гора», Шахтау - «царь-гора», - рассказала моя собеседница. - Ещё в прежние времена говорили, что придёт пора, когда недобрые люди захотят уничтожить горы для своей надобности и выгоды. Вон ведь - ничего уж от Шахтау не осталось, один котлован. Всё соду добывают. Так ведь и царя мы давно уже над собой не знаем. Ещё говорили: если потеряем мы Парную гору, то раздоры начнутся меж людьми. Если Сердце-гора перестанет жить-биться, то станем мы глухи и слепы к чужим бедам. А если падёт Крепость-гора, то тут и всем нашим силам конец придёт. Там и до конца мира недалеко. Вот так-то. Вы уж постарайтесь, дети, наши горы сохранить!»2.

Несколько лет судьба шиханов висела на волоске. Власти или молчали, или не могли решить проблему, обстановка накалялась, в народе зрели протестные настроения. Поскольку вопрос оставался открытым, не продвигалось и освоение туристического пространства территории. «Само отношение к горе Торатау в последние десятилетия свидетельствует о том, что граждане не относятся к ней, как к святыне. Это обычное место для туризма и «отдыха» (шашлыки, пьянство, бутылки, окурки и т. д.). Ни мусульмане, ни православные к своим святым местам подобным образом не относятся, и другим не позво-

\footnotetext{
1 Угроза потери башкирских шиханов. // Сайт БОД «Кук Буре» [Электронный ресурс] URL: http://kyk-byre.ru/154-ugroza-poteri-bashkirskix-shixanov.html (проверено 17.09.2020).

2 Легенда о шиханах // Социальная сеть «В контакте» [Электронный ресурc] URL: https://vk.com/wall-187565013_1866 (проверено 17.09.2020).
} 
ляют. Это в очередной раз свидетельствует, что в общественном сознании горы не ассоциируются со святыми местами, потому что, вероятно, таковыми не являются» ${ }^{1}$. «Спрашивается: кто мешал проложить на шиханах эколого-просветительские маршруты выходного дня? При устойчивом интересе к горам как мировому тренду мало использовалась культурная сокровищница башкирского рода юрматы и населяющих Стерлитамакский и Ишимбайский районы народов. Торатау давно облюбовали скалолазы и парапланеристы, так почему здесь до сих пор не устраиваются массовые спортивные мероприятия? К сожалению, не нашлось закоперщиков и для использования историко-культурного потенциала этого места для развития таких востребованных направлений, как молодежные конкурсы, слеты, патриотические, семейные, бардовские фестивали» ${ }^{2}$.

Шиханы в 2014 году стали местом, где самоорганизовалось движение БОО «Башкорт», ядро которого составили активисты БОД «Кук Буре»: «В марте 2014 года из рядов «Кук буре» демонстративно выходят сразу три заместителя председателя Алчинов Ф., Байназаров Р. и Габбасов Р., раскритиковав политику А. Сальманова в организации» 3 . Формальным поводом для этого стало несогласие с курсом А. Сальманова. По выражению Руслана Габбасова: «Нам казалось, «Кук буре» топчется на одном месте. Мы развитие видели по-другому: нужно было открывать филиалы в районах республики, привлекать молодежь, работать с ней, проводить крупные мероприятия. Например, Дни башкирской молодежи как СБМ в 2010 году провел, после этого никто не проводил. Сколько раз говорили председателю организации Азату Сальманову: «Давай инициативу перехватим», но он не особо горел желанием» 4 .

И вот уже на дворе 2015 год. БОО «Башкорт» зарабатывает авторитет у молодежи, раскручивает организацию ${ }^{5}$. «Было много акций... Митинг в защиту башкирского языка, где собрались 3 тысячи человек. После этого проводили флешмобы «Кольцо жизни» возле шихана Торатау... Дни башкирской молодежи, где собирались около 5 тысяч человек. Проводили спортивные мероприятия, боролись с алкоголизмом» 6 . К числу наиболее значимых можно отнести практику проведения йыйынов (съезды башкирского народа) около шиханов и в различных районах республики. Привлечение к активной национальнополитической деятельности молодежи осуществлялось посредством возрождения древней традиции башкирского самоуправления с учетом современных реалий. Это были сходы жителей башкирской национальности, «где лидеры обещали деревенским обывателям легкое решение их социальных проблем,

1 Башкирия без шиханов: решится ли Рустэм Хамитов на операцию по удалению? Новости Уфы и Башкирии $\operatorname{Pr} / /$ Сайт Живой Журнал. Livejournal.com [Электронный pecypc] URL: https://kolybanov.livejournal.com/5819828.html (проверено 17.09.2020).

2 Tоратау время сберегать // Портал Яндекс Дзен. [Электронный ресурс] URL: https:// zen.yandex.ru/media/panoramarb/tratau-vremia-sberegat-5ab4d3b89e29a2bca9a7ec47 (проверено 17.09.2020).

3 Об отморозках // Сайт Живой Журнал. Livejournal.com [Электронный ресурс] URL: https://anxafiz.livejournal.com/73464.html (проверено 17.09.2020).

4 Председатель «Башкорт» Фаиль Алчинов: «Хамитова критикуем, но в республике нет кандидатуры на его место» // Электронный журнал Proufu.ru [Электронный pecypc] URL: https://proufu.ru/news/society/54098-predsedatel_bashkort_fail_alchinov_khamitova_ kritikuem_no_v_respublike_net_kandidatury_na_ego_mesto/ (проверено 17.09.2020).

5 Об отморозках // Сайт Живой Журнал. Livejournal.com [Электронный ресурс] URL: https://anxafiz.livejournal.com/73464.html (проверено 17.09.2020).

6 Фаиль Алсынов: «Кто-то пытается устроить войну между татарами и башкирами» // Онлайн газета «Реальное время». [Электронный ресурc] URL: https://realnoevremya.ru/ articles/176232-pochemu-v-ufe-zapretili-boo-bashkort (проверено 17.09.2020). 
будоражили их сознание сепаратистскими идеологемами и не скрывали идей «Взять власть в свои руки»... Попытки вступить в ними в диалог со стороны муниципальных властей сопровождались ухмылками со стороны активистов, которые прямо говорили о том, что теперь «они здесь настоящая власть» и угрозами привезти на акции протеста «несколько тысяч башкир». Любых несогласных с их деятельностью они тут же объявляли «врагами башкирского народа» ${ }^{1}$.

Организация «Башкорт» начала превращаться в реальную политическую силу регионального масштаба. Отличительной её особенностью стал умеренный правовой нигилизм. Лидеры БОО «Башкорт» призывали башкир активно переходить к самоуправлению, фактически это означало «брать власть в свои руки» на основе обычного права решать вопросы местного значения: «В последние годы перед нашим народом встали огромные трудности, он пережил много потерь. Народные сходы, проведенные в районах, дали толчок к пробуждению национального самосознания, к активным действиям, к поиску путей разрешения возникающих проблем. Если мы хотим изменить положение нашего народа в лучшую сторону, то мы должны сами взяться за работу» 2 . Активисты «высказывали лозунги об ущемлении прав лиц башкирской национальности органами государственной власти, а также призывы к выходу Башкирии из состава России. Также, в группе «Башкорт» в социальной сети публиковались высказывания о нарушении территориальной целостности России и создании единого исламского государства» ${ }^{3}$.

Сами же лидеры БОО «Башкорт» были очень аккуратны в высказываниях и не выходили за пределы правового поля, умело используя пробелы в законодательстве. По этой причине в течение длительного времени организации и их лидерам удавалось избегать экстремистских статей. Если суммировать ключевые понятия лозунгов БОО «Башкорт», то мы получим следующий набор: предприятия, природные ресурсы, суверенитет, язык, этническая однородность, ислам, шиханы и экология. Как видим, политические лозунги перемежаются с неполитическими. Этот фактор значительно расширил аудиторию движения и вовлек в акции протеста значительные массы населения.

В связи с этим возникает вопрос: что именно подвигло жителей поддерживать акции протеста и участвовать в протестной активности? Ответ на него не может сводиться лишь к простой констатации социально-экономического кризиса. На наш взгляд, проблема намного глубже и серьёзней и связана она с трансформацией общества по нескольким основным направлениям:

1. Республика Башкортостан заметно отстает в области создания условий для проведения культурного досуга. Особенно это касается сельской местности. В результате этого участие в акциях протеста, особенно около шиханов, превращается для жителей в форму активного отдыха, который сопровождается неформальным общением. В таких условиях внешнее формализованное воздействие со стороны органов государственной власти усиливает стремление к поддержке и участию в акциях протеста.

2. Ритуализация и карнавализация протестной активности. Для этого доста-

1 Почему деятельность «Башкорт» признали экстремистской // Сайт Gorobzor.ru [Электронный ресурс] URL: https://gorobzor.ru/blogi/m-mardanov/pochemu-deyatelnostbashkort-priznali-ekstremistskoy (проверено 17.09.2020).

2 В традициях «святых 90-х» «Башкорт» готовит наезд // Сайт Живой Журнал. Livejournal. com [Электронный ресурс] URL: https://quis-quaeritis.livejournal.com/77049.html (проверено 17.09.2020).

3 БОО «Башкорт» признана экстремистской организацией // Электронный журнал Proufu.ru [Электронный ресурс] URL: https://proufu.ru/news/society/93010-boo_bashkort_ priznana_ekstremistskoy_organizatsiey/ (проверено 17.09.2020). 
точно вспомнить, как встречали Ф. Алчинова, когда он выходил после краткосрочных задержаний: «Встретить народного избранника приехали более 60 человек со всей республики, в числе которых были дети и инвалид-колясочник. Сам мужчина вышел к друзьям в национальном башкирском костюме и произнес слова благодарности за поддержку» ${ }^{1}$. Данный символизм и элемент карнавальности подобных действий был направлен на формирование у аудитории подсознательного ощущения, что в лице Ф. Алчинова преследуются башкиры в целом, превращая его в символ башкирского сопротивления «несправедливости», преобразуя свободное социальное поведение представителей башкирского этноса в обязательную и регламентированную поддержку.

3. В течение длительного времени, особенно это касается сельского башкирского населения, не создавались хорошие материальные условия и стимулы к труду. Сельские жители, особенно башкиры, начали привыкать к своему низкому материальному благосостоянию. В результате этого ценность начали приобретать предметы и явления неэкономического характера (спокойная жизнь, горы, язык, мифы, шежере и т.д.). В их поддержке происходит самовыражение и самореализация башкирского этноса.

4. Протестная активность в Республике Башкортостан имеет и институциональную специфику. Дело в том, что активные участники протестов около шиханов в основном сельские жители, которые в силу специфики рода занятий не вовлечены в иерархию бюрократизированных организаций с жестким регламентом трудовой повинности и отдыха. Их график жизни более гибкий. В результате этого у них больше времени для восприятия ценностей постмодернизма, например, лозунгов за экологию и сохранение родного языка. В результате этого вместо ценности промышленно-экономических достижений в качестве высшего приоритета в общественном сознании преобладают идеи спокойной жизни, её качества, этнокультурные обычаи. Жесткая дисциплина, повиновение, самоотверженность в труде и приоритет материального, при всей архаичности жизни, сменяются постиндустриальными идеями индивидуального выбора и самовыражения в протесте против промышленного роста, а значит экономических достижений, от которых местному населению нет никакой видимой пользы, а только проблемы.

5. Активизация участия горожан в протестном движении связана с изменением характера занятости и оплачиваемой работы. Рабочие графики горожан становятся более гибкими исходя из современного уровня социального и технического развития общества. Всё более широко распространяется сменный график работы, неполная и частичная занятость, оптимизируется, таким образом, количество рабочих часов и увеличивается количество свободного неоплачиваемого времени. Иными словами, происходит трудовое расслоение общества, одни члены которого заняты в эффективно организованном производстве и политическом управлении, а другие посвящают свое свободное время протесту, который становится формой самореализации и развлечения. Этот процесс получил дополнительный стимул в 2020 году в результате введения режима самоизоляции и карантина, в результате которого горожане не смогли съездить в отпуск зарубеж. В результате этого участие в протесте стало одним из аспектов расширения досуговой деятельности горожан в условиях неразвитой инфраструктуры проведения отдыха как отрасли эконо-

1 Лидер защитников Куштау Фаиль Алчинов вышел на свободу // Сайт Новости Башкирии [Электронный ресурс] URL: https://newsbash.ru/society/zakon/20697-liderzaschitnikov-kushtau-fail-alchinov-vyshel-na-svobodu.html (проверено 17.09.2020). 
мики. Следует отметить, что шиханы являются не только местом образования БОО «Башкорт», но и местом досуга.

6. Коммуникативный аспект участия в протестном движении связан с тем, что приоритет накопления материальных ценностей сменился приоритетом информации. В связи с этим сельские и городские жители начали манипулировать не материальными предметами или их количественным измерением, а их качественными характеристиками (символами, идеями, образами, знаниями и т.д.). Это порождает изменения в сознании жителей Республики Башкортостан, в национальной и культурной жизни, характере взаимодействия, порождения и интерпретации светских и религиозных мифов. Вступая в процесс общения в социальных сетях или «Ватсап», человек легче усваивает новые ценности при сохранении старых в снятом, подчиненном виде. По этой причине коммуникация начинает строиться в два этапа, сначала удаленное взаимодействие, в рамках которого осуществляется восприятие ценностей, а затем непосредственный контакт в ходе акта протеста, в ходе которого ценности закрепляются. Так на современном этапе формируется протестная среда, в которой преобладает консенсус по определенным вопросам и ценностям. Иными словами, чем интенсивнее развивается пользовательское информационное общество по уровню социального, экономического, технического и политического развития, тем интенсивнее становятся протесты.

7. Произошло разочарование населения в использовании информационных технологий для решения конкретных проблем. Всемирная паутина как громоотвод протестной активности постепенно теряет свое значение, потому что власть реагирует на протестные заявления в Интернете избирательно. Он постепенно утрачивает свое значение как форма самореализации протестной активности индивида, которая теряется в обилии информации. В связи с этим протестная активность становится в наше время все более распространенной и доступной формой давления на власть по тем или иным вопросам, превращаясь в норму. От участия в акциях протеста теперь не застрахован никто, например, из-за уплотнения городской застройки или обмана при долевом строительстве.

8. Происходит профессионализация протестной активности. Она выражается в том, что чем больше на протяжении жизни человек самореализуется посредством протестной активности, тем сильнее у него тяга к ним и более выражена установка на участие в организованном протесте. Желание участвовать в несанкционированных акциях есть рычаг протестной активности, предполагающей особое взаимодействие личности с государством и заинтересованными группами. Сопротивление является одним из аспектов социализации и адаптации населения к новым условиям.

Подводя итоги, необходимо обратить внимание на то, что в течение почти всего XX века человек мог родиться, жить и умереть, не участвуя ни в каких акциях протеста. Начиная с 90 -х годов XX века человек, родившийся в одной политической и социально-экономической реальности, живет в другой, а умирает в третьей. При этом он никак не застрахован от несправедливости, реакцией на которую является участие в акциях протеста. При этом на росте протестной активности сказываются экономические, социальные и политические процессы, происходящие в обществе. Современный человек перестает быть просто рабочей силой, он начинает осознавать, что от него зависит множество факторов современной экономики и политики. В частности, позиция региональных властей по отношению к тем или иным экономическим или политическим вопросам, которые можно продавить с помощью протеста. Учитывая, что регион национальный, протестная активность превращается в этнохарак- 
теристику и тактику достижения поставленных целей отдельными группами и этносами.

Статья публикуется при поддержке Школы молодого этнополитолога в Республике Башкортостан (грант Фонда президентских грантов 19-2-022447).

\section{Список литературы}

Башкирия без шиханов: решится ли Рустэм Хамитов на операцию по удалению? - Новости Уфы и Башкирии Pr // Сайт Живой Журнал. Livejournal.com [Электронный ресурс] URL: https://kolybanov.livejournal.com/5819828.html (Дата обращения 17.09.2020).

БОО «Башкорт» признана экстремистской организацией // Электронный журнал Proufu.ru [Электронный ресурс] URL: https://proufu.ru/news/ society/93010-boo_bashkort_priznana_ekstremistskoy_organizatsiey/ (Дата обращения 17.09.2020).

В традициях «святых 90-х» «Башкорт» готовит наезд // Сайт Живой Журнал. Livejournal.com [Электронный pecypc] URL: https://quis-quaeritis.livejournal. com/77049.html (Дата обрашения 17.09.2020).

Легенда о шиханах // Социальная сеть «В контакте» [Электронный ресурс] URL: https://vk.com/wall-187565013_1866 (Дата обращения 17.09.2020).

Лидер защитников Куштау Фаиль Алчинов вышел на свободу // Сайт Новости Башкирии [Электронный ресурс] URL: https://newsbash.ru/society/ zakon/20697-lider-zaschitnikov-kushtau-fail-alchinov-vyshel-na-svobodu.html (Дата обращения 17.09.2020).

Об отморозках // Сайт Живой Журнал. Livejournal.com [Электронный ресурс] URL: https://anxafiz.livejournal.com/73464.html (Дата обращения 17.09.2020).

Почему деятельность «Башкорт» признали экстремистской // Сайт Gorobzor. ru [Электронный ресурс] URL: https://gorobzor.ru/blogi/m-mardanov/pochemudeyatelnost-bashkort-priznali-ekstremistskoy (Дата обращения 17.09.2020).

Председатель «Башкорт» Фаиль Алчинов: «Хамитова критикуем, но в республике нет кандидатуры на его место» // Электронный журнал Proufu.ru [Электронный ресурс] URL: https://proufu.ru/news/society/54098-predsedatel_ bashkort_fail_alchinov_khamitova_kritikuem_no_v_respublike_net_kandidatury_ na_ego_mestō/ (Дата обращения 17.09.2020).

Торатау время сберегать // Портал Яндекс Дзен. [Электронный ресурс] URL: https://zen.yandex.ru/media/panoramarb/tratau-vremia-sberegat5ab4d3b89e29a2bca9a7ec47 (Дата обращения 17.09.2020).

Угроза потери башкирских шиханов. // Сайт БОД «Кук Буре» [Электронный pecypc] URL: http://kyk-byre.ru/154-ugroza-poteri-bashkirskix-shixanov.html (Дата обращения 17.09.2020).

Фаиль Алсынов: «Кто-то пытается устроить войну между татарами и башкирами» // Онлайн газета «Реальное время». [Электронный ресурc] URL: https:// realnoevremya.ru/articles/176232-pochemu-v-ufe-zapretili-boo-bashkort (Дата обращения 17.09.2020). 
ROMANOV Sergey Yur'evich, Cand.Sci. (Philos.), Senior Researcher at the Center for Humanitarian Studies of the Ministry of Culture of the Republic of Bashkortostan (13/1 M. Gafuri St., Ufa, 450076, Russia; romser76@yandex.ru) YUSUPOV II'shat Faritovich, Cand.Sci. (Soc.), Research Associate at the Center for Socio-Cultural Analysis, Institute for Strategic Studies of the Republic of Bashkortostan (15 Kirova St., Ufa, 450008, Russia; ilshat_iosopov@mail.ru) SALIMGAREEV Denis Igorevich, postgraduate student in the third year of study at the Faculty of Philosophy and Sociology of Bashkir State University, (3/4 K. Marks St; Ufa, Republic of Bashkortostan, 450076, Russia; remus-102@mail.ru)

\title{
SOCIOLOGICAL ASPECTS OF PROTEST ACTIVITY IN THE REPUBLIC OF BASHKORTOSTAN AT THE MODERN STAGE
}

\begin{abstract}
Based on the analysis of the dynamics of the situation around the shikhan mountains, the article reveals the reasons and factors for the growth of protest activity of the population in the Republic of Bashkortostan. According to the authors, a unique socio-cultural environment for protest activity has formed in the region, the originality of which lies in the fact that any socially significant issue or everyday conflict instantly acquires a national or confessional connotation, overgrows with myths and rumors, and undergoes sacralization.
\end{abstract}

Keywords: protest activity, shihans, sociocultural environment, factors of protests.

СЕЛИВАНОВ Сергей Григорьевич - доктор технических наук, профессор Уфимского государственного авиационного технического университета (450000, Республика Башкортостан, Уфа, ул. Карла Маркса, 12; S.G.Selivanov@таil.ru)

САВИЧЕВ Владимир Леонидович - доцент, кандидат политических наук, г. Уфа, исполнительный директор проекта «Школа молодого этнополитолога в Республике Башкортостан» (450076, Республика Башкортостан, Уфа, ул.Космонавтов, 1; vlsufa@yandex.ru

\section{НОВАЯ ЭТНОПОЛИТИЧЕСКАЯ ТЕХНОЛОГИЯ: «ДУДА И ДУДОЧКА»}

Аннотация. В статье рассматриваются тенденции применения политических технологий «самозванства» в прошлом и настоящем применительно к ситуации в Республике Беларусь. Там накопились противоречия в развитии экономики, общества, государственности. Неготовность власти к модернизации консолидирующей идеи и сохранение прежней модели политического управления не способны разрешить возникшие проблемы, особенно в условиях, когда в Польше есть политические силы, заинтересованные в дестабилизации ситуации и смене в Беларуси политического режима.

Ключевые слова: Беларусь, политические технологии, консолидирующая идея, Лукашенко

B се хорошо помнят технологию проникновения во власть, которой закончилась Троянская война. Когда прямая интервенция не удалась, и безрезультатно завершились бои с войском троянцев и их союзников, хитроумный Одиссей изобрёл метод «троянского коня», который сработал.

Сущность этого метода не только и даже не столько в том, что действительно из дерева была построена гигантская фигура коня, внутри которой спрятался сын Ахиллеса с другими храбрыми воинами, а в том, что помог им изнутри открыть город изменник - один из девятнадцати сыновей царя Приама - 